\title{
Evaluation Of Customer Survey Data To Develop An Effective Marketing Plan For State Parks: A Case Study Using The Texas Parks And Wildlife Department State Park Study
}

Marcy Beverly, Sam Houston State University, USA Michael Lau, Sam Houston State University, USA

Kyle Stutts, Sam Houston State University, USA

Dominick Fazarro, Sam Houston State University, USA

\begin{abstract}
The Texas Parks and Wildlife Department (TPWD) collected information from 2001-2007 from individual parks throughout Texas in an effort to gain useful marketing information from its customers. This project was the first to survey the majority of state parks in Texas in order to gain a system-wide understanding of state park visitors to help plan for state-wide and regional marketing strategies in the future. This survey project collected data from state park visitors such as demographics, whether they were overnight or day visitors, and season of visit in order to identify distinct patterns. Most visitors to the parks were white/non-Hispanic (92\%) despite the fact that this category makes up only about half of the Texas population. There were 13\% of park visitors from outside the state of Texas and these visitors were older than the average resident Texan visitor and had a lower household income. The data from this survey will allow TPWD to develop specific marketing strategies to increase attendance, revenue, and customer satisfaction at state parks. Specifically, the information will aid in identifying a specific target market on which TPWD should concentrate its efforts.
\end{abstract}

Keywords: Park demographics, State park case study, Customer survey data

\section{INTRODUCTION}

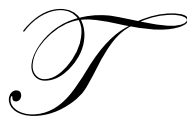

he purpose of the state-wide Texas Parks and Wildlife Department (TPWD) visitor survey was to gain useful marketing information for Texas State Parks. Topics covered in the survey included visitor demographics, visitation patterns, reasons for visiting the park, facilities used at the park, and customer satisfaction with their visit. This survey project collected data over an entire year so that seasonal trends for all Texas state parks could be evaluated. The data set included information from 67 Texas state parks that were surveyed from 2001-2007. This report focuses on the demographics of the visitors to Texas State Parks.

\section{DATA COLLECTION METHODOLOGY}

Park staff and volunteers distributed questionnaires in the parks from 2002 to 2007 . Three waves of surveys were conducted with each wave lasting one year in duration. The first wave of the survey began in November 2002 and ended in October 2003. The second wave was from June 2004 through May 2005 and the final wave began in September 2006 and ended in August 2007. 
Park staff that distributed the questionnaires was provided detailed information on how to randomly distribute surveys to ensure adequate representation of state park visitors at each park. Visitors were approached in the park and were asked to complete and return the questionnaire. Visitors were given the option to return the questionnaire at the park office or survey drop box or to mail the questionnaire to Austin Headquarters.

The goal for each park was to complete 200 surveys per three-month season or 800 surveys for the year. Based on an estimated 30\% response rate, the goal was for park staff to distribute approximately 60 surveys per week at most parks. Questionnaires were to be distributed based on the proportion of day to overnight visitors at each park reported by the State Parks Division. Simple random sampling procedures were followed to ensure that the customers who received the questionnaire were representative of the entire population of state park visitors.

\section{SURVEY RESULTS}

This report presents results for the total sample of survey respondents as well as results for visitors during each season. Results for the total sample of all state parks have been weighted by type of visitor (overnight or day) as well as season of visit. This was done to ensure that the survey samples represented the actual visitation rates determined by TPWD. The seasons of visitation were defined as follows:

\begin{tabular}{|c|c|}
\hline Season & Range in Months \\
\hline Winter & December - February \\
\hline Spring & March - May \\
\hline Summer & June - August \\
\hline Fall & September - November \\
\hline
\end{tabular}

Statistical differences between day and overnight visitors and season of visit are bolded in the figures and tables shown in this report.

Figure 1: Visitors' Place of Residence

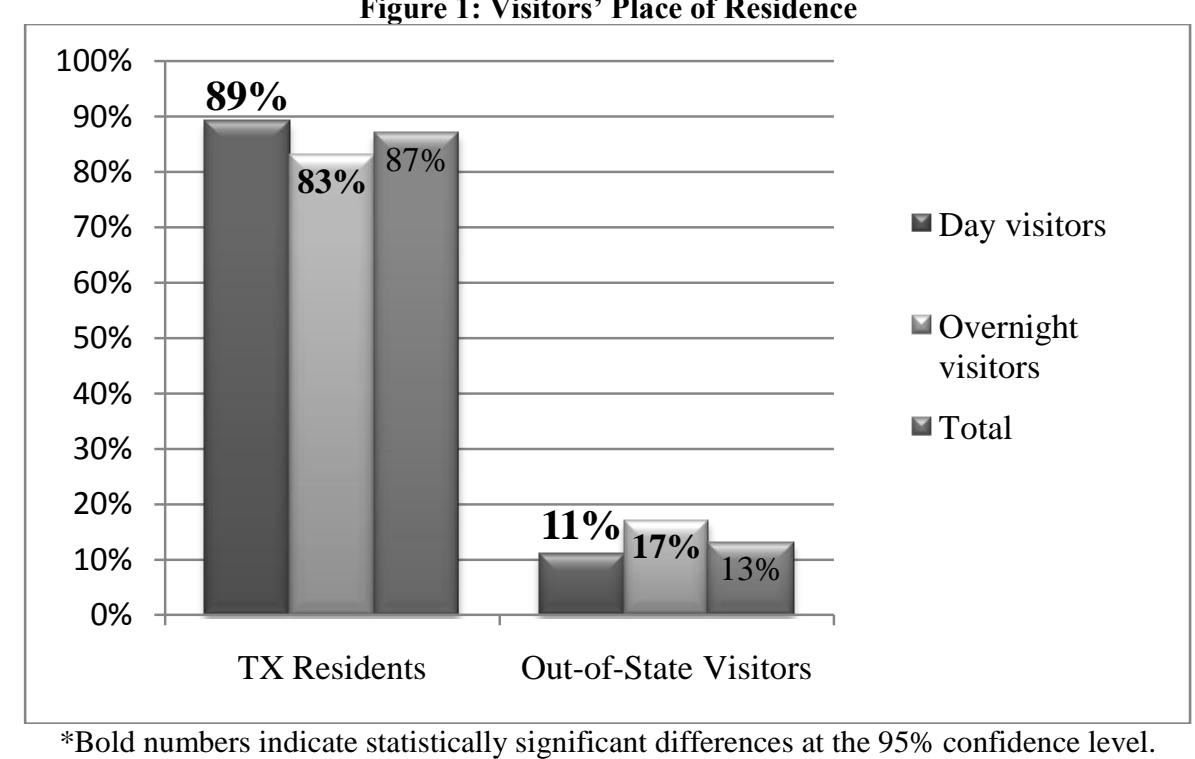

\section{VISITOR DEMOGRAPHICS AND COMPARISON TO THE GENERAL TEXAS POPULATION}

Eighty-seven percent of all visitors to state parks were Texas residents (Figure 1). Out-of-state visitors accounted for $17 \%$ of all overnight visitors and $11 \%$ of all day visitors to the parks. This was expected as out-of- 
state visitors are more likely to spend the night because of distances traveled. Only $11 \%$ of Texas residents who visited a park stayed overnight.

Sixty-eight percent of state park visitors lived in urban areas of Texas and $20 \%$ of visitors resided in rural areas of Texas (Table 1). Eleven percent of visitors were from other U.S. states and 1\% of visitors were international. The winter and spring seasons had the highest percentage of international visitors and the highest percentage of visitors from other U.S. states. This is likely due to visitors traveling to Texas to enjoy the milder winters compared to those experienced by other states.

Table 1

Visitors' Place of Residence by Season of Visit

\begin{tabular}{|l|c|c|c|c|c|}
\hline & Winter & Spring & Summer & Fall & Total \\
\hline Texas - Urban & $60 \%$ & $67 \%$ & $69 \%$ & $73 \%$ & $68 \%$ \\
\hline Texas - Rural & $17 \%$ & $19 \%$ & $23 \%$ & $17 \%$ & $20 \%$ \\
\hline Other US State & $21 \%$ & $12 \%$ & $7 \%$ & $9 \%$ & $11 \%$ \\
\hline International & $2 \%$ & $2 \%$ & $1 \%$ & $1 \%$ & $1 \%$ \\
\hline
\end{tabular}

Table 2

Age (18+): Comparison of Texas Survey Respondent Demographics to TX Population

\begin{tabular}{|l|c|c|}
\hline & Visitors who live in TX & TX population (2000 Census) \\
\hline $\mathbf{2 4}$ and under & $4 \%$ & $15 \%$ \\
\hline $\mathbf{2 5}-\mathbf{3 4}$ & $14 \%$ & $21 \%$ \\
\hline $\mathbf{3 5}-\mathbf{4 4}$ & $25 \%$ & $22 \%$ \\
\hline $\mathbf{4 5}-\mathbf{5 4}$ & $25 \%$ & $17 \%$ \\
\hline $\mathbf{5 5}-\mathbf{6 4}$ & $19 \%$ & $11 \%$ \\
\hline $\mathbf{6 5}$ and older & $13 \%$ & $14 \%$ \\
\hline Average age & 47.3 & 43.3 \\
\hline Median age & 47.0 & 40 \\
\hline
\end{tabular}

Table 3

Resident Texan Visitors' Age (18+) by Season of Visit

\begin{tabular}{|l|c|c|c|c|}
\hline & Winter & Spring & Summer & Fall \\
\hline $\mathbf{2 4}$ and under & $6 \%$ & $3 \%$ & $4 \%$ & $3 \%$ \\
\hline $\mathbf{2 5}-\mathbf{3 4}$ & $15 \%$ & $15 \%$ & $15 \%$ & $14 \%$ \\
\hline $\mathbf{3 5}-\mathbf{4 4}$ & $23 \%$ & $26 \%$ & $26 \%$ & $23 \%$ \\
\hline $\mathbf{4 5}-\mathbf{5 4}$ & $25 \%$ & $24 \%$ & $25 \%$ & $25 \%$ \\
\hline $\mathbf{5 5}-\mathbf{6 4}$ & $19 \%$ & $18 \%$ & $18 \%$ & $21 \%$ \\
\hline $\mathbf{6 5}$ and older & $12 \%$ & $14 \%$ & $12 \%$ & $14 \%$ \\
\hline Average age & 47.0 & 47.1 & 46.8 & 48.4 \\
\hline Median age & 47.0 & 46.0 & 46.0 & 48.0 \\
\hline
\end{tabular}

\section{$\underline{\text { Age }}$}

Park visitors who lived in Texas (47 years) were, on average, older than the general population (43 years) of adult Texas residents (Table 2). The percentage of visitors age 35-64 was much higher for park visitors (69\%) compared to the general Texas population (50\%). Only $18 \%$ of park visitors were below the age of 35 compared to $36 \%$ of the general Texas population. The number of young adult visitors (under 35) was significantly lower compared to the Texas population of young adults.

The age and age distribution of Texas resident visitors had very little variation among the four seasons of the year. Six percent of visitors during the winter were age 24 and under, the highest among all seasons (Table 3 ). The average age of visitors in the fall was higher (48 years age) than the other three seasons. These data indicate that the target market age for state parks does not change seasonally. 
There were distinct differences in the distribution of ages between day and overnight visitors. Forty-four percent of overnight visitors were age 55 or older compared to only $32 \%$ of day visitors (Table 4). On average, day (47.2) visitors were approximately four years younger than overnight (51.4) visitors.

Table 4

Age (18+) Comparison of Day and Overnight Visitors

\begin{tabular}{|l|c|c|}
\hline & Day Visit & Overnight Visit \\
\hline $\mathbf{2 4}$ and under & $5 \%$ & $3 \%$ \\
\hline $\mathbf{2 5}-\mathbf{3 4}$ & $15 \%$ & $20 \%$ \\
\hline $\mathbf{3 5}-\mathbf{4 4}$ & $24 \%$ & $23 \%$ \\
\hline $\mathbf{4 5}-\mathbf{5 4}$ & $24 \%$ & $\mathbf{2 4 \%}$ \\
\hline $\mathbf{5 5}-\mathbf{6 4}$ & $\mathbf{1 9 \%}$ & $\mathbf{2 0 \%}$ \\
\hline $\mathbf{6 5}$ and older & $\mathbf{1 3 \%}$ & 51.4 \\
\hline Average age & 47.2 & $\mathbf{5 2}$ \\
\hline Median age & 47.0 & \\
\hline
\end{tabular}

*Bold numbers indicate statistically significant differences at the $95 \%$ confidence level.

\section{$\underline{\text { Ethnicity }}$}

The vast majority $(85 \%)$ of park visitors that resided in the state of Texas were white/non-Hispanic (Table 5). This percentage is much higher than the percentage of white/non-Hispanics in the general population of Texas $(53 \%)$. Both Hispanics and black/non-Hispanics were greatly underrepresented in the visitors to the state parks compared to their contribution to the general population of the state of Texas.

Table 5

Ethnicity: Comparison of Texas Survey Respondent Demographics to TX Population

\begin{tabular}{|l|c|c|}
\hline & Visitors who live in TX & TX population (2000 Census) \\
\hline White/Non-Hispanic & $\mathbf{8 5 \%}$ & $\mathbf{5 3 \%}$ \\
\hline Hispanic & $\mathbf{1 1 \%}$ & $\mathbf{3 2 \%}$ \\
\hline Black/Non-Hispanic & $\mathbf{1 \%}$ & $\mathbf{1 1 \%}$ \\
\hline Other & $3 \%$ & $3 \%$ \\
\hline
\end{tabular}

*Bold numbers indicate statistically significant differences at the $95 \%$ confidence level.

White/non-Hispanic was the predominant group represented by state park visitors in each season of the year (Table 6). There were no significant differences in ethnicity among the four seasons.

Table 6

Resident Texan Visitors' Ethnicity by Season of Visit

\begin{tabular}{|l|c|c|c|c|}
\hline & Winter & Spring & Summer & Fall \\
\hline White/Non-Hispanic & $87 \%$ & $86 \%$ & $84 \%$ & $87 \%$ \\
\hline Hispanic & $8 \%$ & $10 \%$ & $12 \%$ & $9 \%$ \\
\hline Black/Non-Hispanic & $1 \%$ & $1 \%$ & $1 \%$ & $1 \%$ \\
\hline Other & $4 \%$ & $3 \%$ & $3 \%$ & $3 \%$ \\
\hline
\end{tabular}

Table 7

Ethnicity: Comparison of Texas Survey Respondent Demographics to TX Population

\begin{tabular}{|l|c|c|}
\hline & Day Visit & Overnight Visit \\
\hline White/Non-Hispanic & $\mathbf{9 1 \%}$ & $\mathbf{9 5 \%}$ \\
\hline Hispanic & $2 \%$ & $0 \%$ \\
\hline Black/Non-Hispanic & $1 \%$ & $1 \%$ \\
\hline Other & $6 \%$ & $4 \%$ \\
\hline
\end{tabular}

*Bold numbers indicate statistically significant differences at the $95 \%$ confidence level. 
White/Non-Hispanic was also the predominant group represented by both day and overnight visitors accounting for $91 \%$ of day visitors and $95 \%$ of overnight visitors (Table 7). There were no significant differences among the different ethnicities in terms of type of visitor (day or overnight).

\section{Urban vs. Rural}

Data in Table 8 reveal that a higher percentage of resident Texan park visitors were from rural areas (23\%) compared to the general population of Texas residents as reported in the 2000 census $(15 \%)$. These data indicate that rural Texas residents are more likely to visit state parks than those who live in the urban areas of the state.

Table 8

Residence: Comparison of Texas Survey Respondent Demographics to TX Population

\begin{tabular}{|l|c|c|}
\hline & Resident Texan park Visitors & TX population (2000 Census) \\
\hline Urban & $77 \%$ & $85 \%$ \\
\hline Rural & $23 \%$ & $15 \%$ \\
\hline
\end{tabular}

The urban/rural pattern was significantly different for the fall season compared to the other three seasons of the year (Table 9). During the fall season, a higher percentage of urban visitors $(81 \%)$ visited state parks resulting in a decrease in the percentage of rural visitors. The highest percentage of rural visitors to state parks occurred during the summer season $(25 \%)$.

Table 9

Resident Texan Visitors' Residence by Season of Visit

\begin{tabular}{|l|c|c|c|c|}
\hline & Winter & Spring & Summer & Fall \\
\hline Urban & $78 \%$ & $78 \%$ & $75 \%$ & $\mathbf{8 1 \%}$ \\
\hline Rural & $22 \%$ & $22 \%$ & $25 \%$ & $\mathbf{1 9 \%}$ \\
\hline
\end{tabular}

*Bold numbers indicate statistically significant differences at the $95 \%$ confidence level.

There were no differences in percentage of urban/rural residents when comparing day and overnight visitors to state parks (Table 10). The percentages of urban and rural residents for day and overnight visitors closely resembled the urban/rural pattern for all visitors combined.

Table 10

Residence: Comparison of Texas Survey Respondent Demographics to TX Population

\begin{tabular}{|l|c|c|}
\hline & Day Visit & Overnight Visit \\
\hline Urban & $78 \%$ & $79 \%$ \\
\hline Rural & $22 \%$ & $21 \%$ \\
\hline
\end{tabular}

Over one-third (36\%) of all park visitors resided in five counties in the state of Texas. These results were weighted and were calculated using the zip code of each state park visitor.

- $\quad$ Harris $(10 \%)$

- $\quad$ Dallas $(8 \%)$

- $\quad$ Tarrant $(7 \%)$

- $\quad$ Travis $(6 \%)$

- $\quad$ Bexar (5\%)

These counties are home to the largest metropolitan areas in Texas. The highest number of visitors came from Harris and Dallas counties, home of the two largest metropolitans in Texas. All other counties contributed less than 3\% to the total. Figure 2 identifies the state parks located in proximity to the Dallas/Fort Worth metropolitan area. 
Figure 2. Parks Located in Proximity to the Dallas/Fort Worth Metropolitan Area

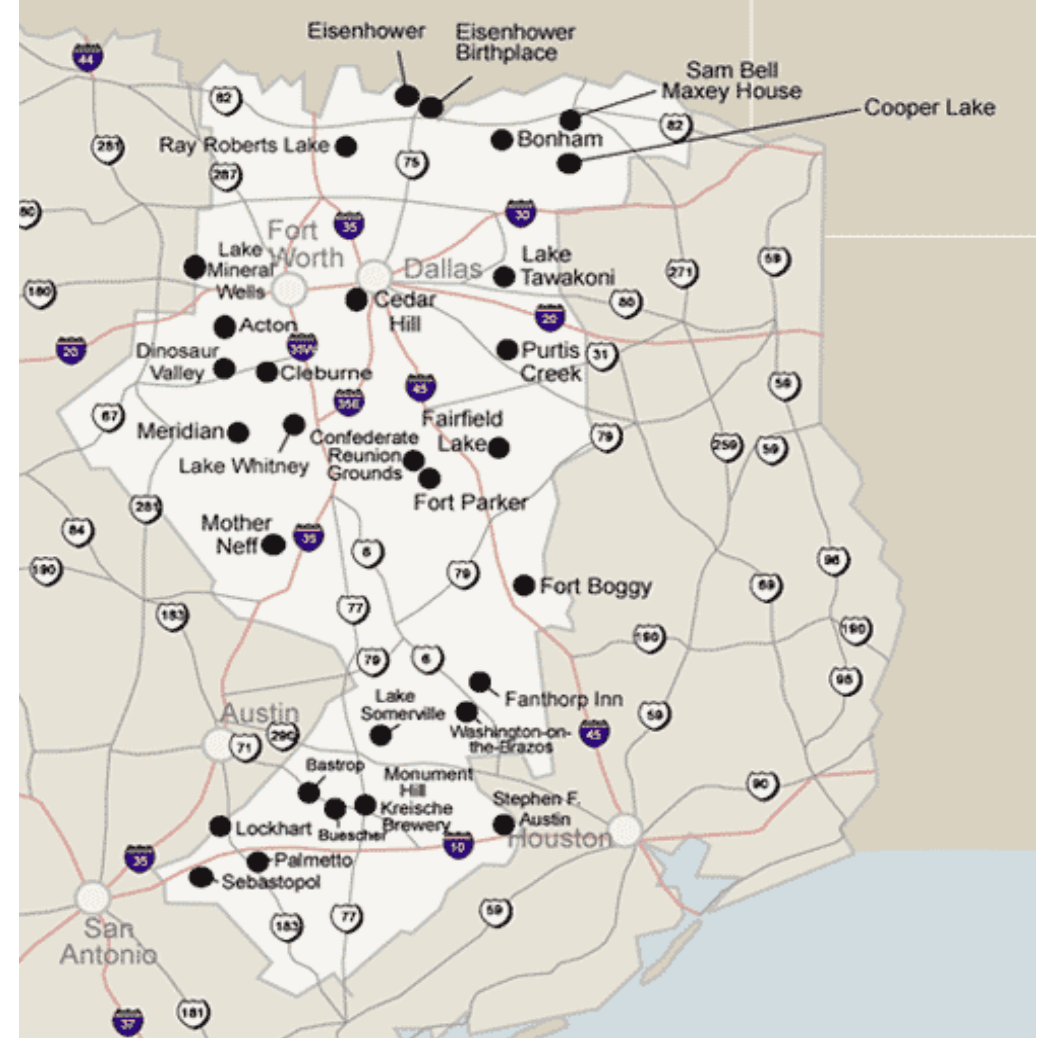

Figure 3 identifies the state parks located in proximity to the Houston metropolitan area.

Figure 3. Parks Located in Proximity to the Houston Metropolitan Area

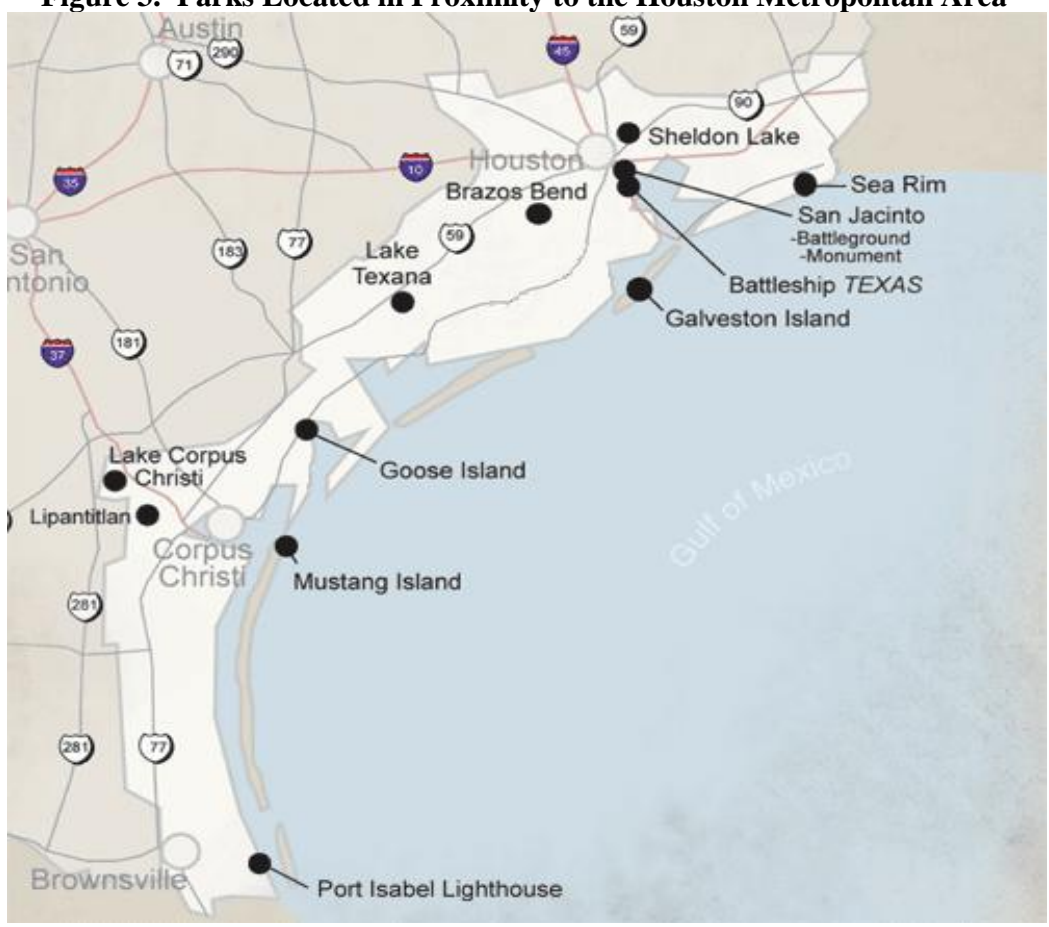


Figure 4 identifies the state parks located in proximity to the Austin/San Antonio metropolitan area.

Figure 4. Parks Located in Proximity to the Austin/San Antonio Metropolitan Area

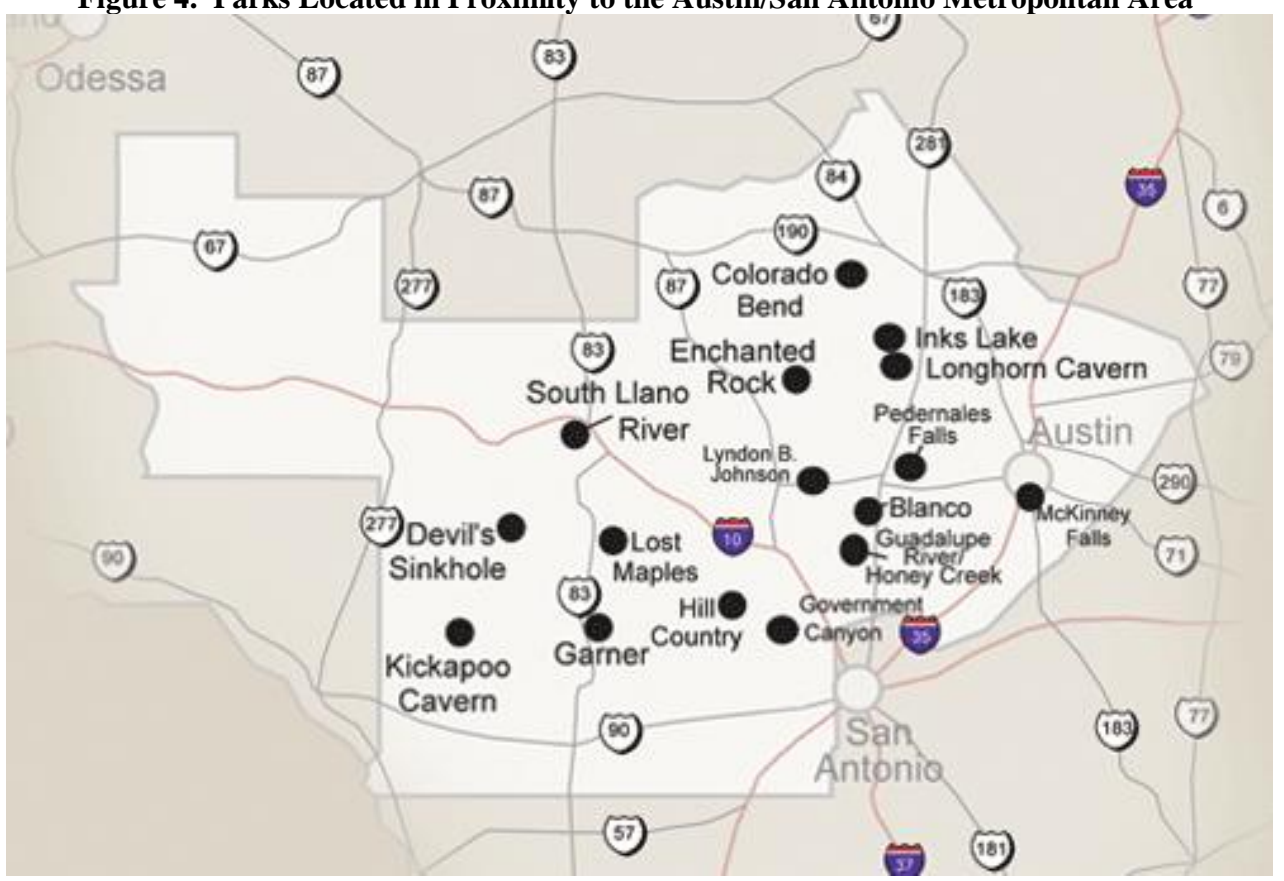

\section{Household Income}

Park visitors from the state of Texas had a higher median household income than the general Texas population and were more likely to earn $\$ 100,000$ or more on an annual basis (Figure 5). The median household income of park visitors was $\$ 60,000-\$ 79,999$ while the median household income of the general population of Texas was $\$ 40,000$. Fifty-three percent of park visitors had an annual household income over $\$ 60,000$, and $20 \%$ of visitors had an annual household income of $\$ 100,000$ or more.

Figure 5: Household Income:

Comparison of Texas Survey Respondent Demographics to TX Population

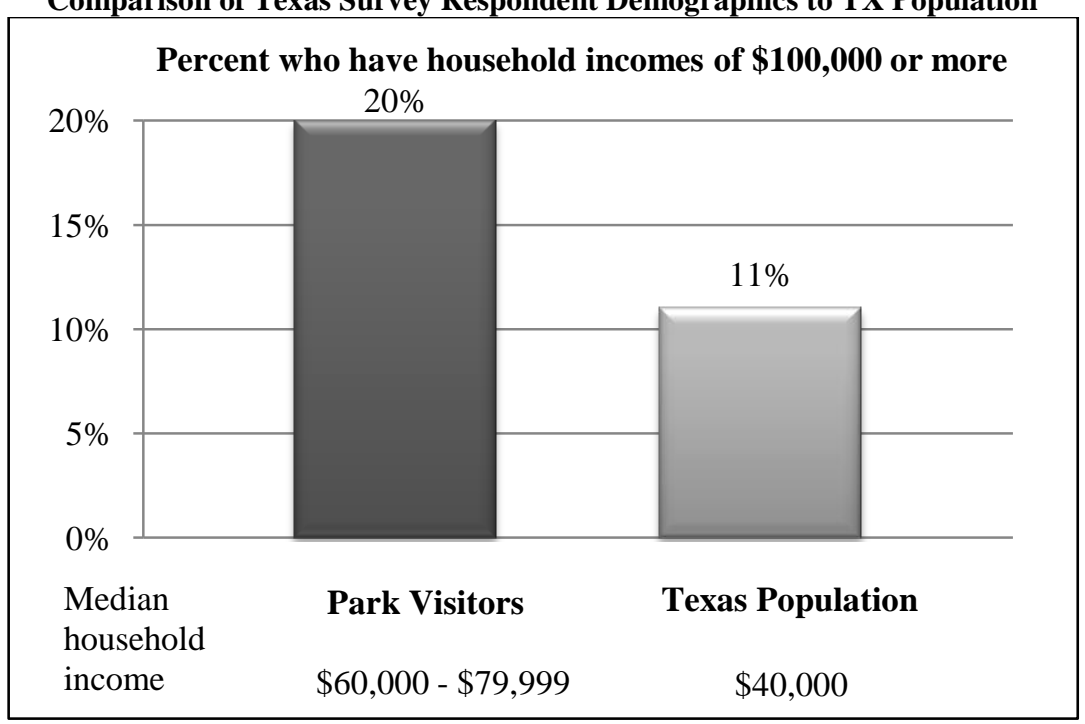


There were no significant differences in incomes of visitors among the four seasons of visitation (Table 11). The summer (17\%) season had the lowest percentage of visitors with an annual income of $\$ 100,000$ or more.

Table 11

Resident Texan Visitors' Household Income by Season of Visit

\begin{tabular}{|l|c|c|c|c|c|}
\hline & Winter & Spring & Summer & Fall & Total \\
\hline Under \$20,000 & $7 \%$ & $7 \%$ & $6 \%$ & $6 \%$ & $6 \%$ \\
\hline $\mathbf{\$ 2 0 , 0 0 0 - \$ 3 9 , 9 9 9}$ & $20 \%$ & $17 \%$ & $18 \%$ & $17 \%$ & $18 \%$ \\
\hline $\mathbf{\$ 4 0 , 0 0 0 - \$ 5 9 , 9 9 9}$ & $22 \%$ & $23 \%$ & $25 \%$ & $23 \%$ & $23 \%$ \\
\hline $\mathbf{\$ 6 0 , 0 0 0 - \$ 7 9 , 9 9 9}$ & $18 \%$ & $18 \%$ & $20 \%$ & $19 \%$ & $19 \%$ \\
\hline $\mathbf{\$ 8 0 , 0 0 0 - \$ 9 9 , 9 9 9}$ & $13 \%$ & $14 \%$ & $14 \%$ & $14 \%$ & $14 \%$ \\
\hline $\mathbf{\$ 1 0 0 , 0 0 0}$ or more & $20 \%$ & $21 \%$ & $17 \%$ & $21 \%$ & $20 \%$ \\
\hline
\end{tabular}

\section{Demographics of out-of-state vs. Texas resident visitors}

There was some variation in age between out-of-state visitors and visitors who lived in Texas (Table 12). The average age of out-of-state visitors (55.8) was greater than that of in-state visitors (47.3). Fifty percent of visitors who lived in Texas were age 35 to 54 compared to only $27 \%$ of out-of-state visitors. A higher percentage of out-of-state visitors (63\%) were 55 or older compared to visitors who lived in Texas (32\%). This difference indicates that separate marketing tactics should be employed when targeting visitors who live in Texas and those that live outside of the state of Texas.

Table 12

Age (18+)

Comparison of Survey Respondent Demographics

\begin{tabular}{|l|c|c|}
\hline & Out-of-state visitors & Visitors who live in TX \\
\hline $\mathbf{2 4}$ and under & $3 \%$ & $4 \%$ \\
\hline $\mathbf{2 5}-\mathbf{3 4}$ & $7 \%$ & $25 \%$ \\
\hline $\mathbf{3 5}-\mathbf{4 4}$ & $11 \%$ & $25 \%$ \\
\hline $\mathbf{4 5}-\mathbf{5 4}$ & $16 \%$ & $19 \%$ \\
\hline $\mathbf{5 5}-\mathbf{6 4}$ & $33 \%$ & $13 \%$ \\
\hline $\mathbf{6 5}$ and older & $30 \%$ & 47.3 \\
\hline Average age & 55.8 & 47 \\
\hline Median age & 59.0 & 2 \\
\hline
\end{tabular}

The ethnic composition of out-of-state visitors was similar to resident Texan visitors (Table 13). Ninetyfive percent of out-of-state park visitors were white/non-Hispanic compared to $92 \%$ for visitors who lived in Texas.

Table 13

Ethnicity

Comparison of Survey Respondent Demographics

\begin{tabular}{|l|c|c|}
\hline & Out-of-state visitors & Visitors who live in TX \\
\hline White/Non-Hispanic & $95 \%$ & $92 \%$ \\
\hline Hispanic & $1 \%$ & $2 \%$ \\
\hline Black/Non-Hispanic & $1 \%$ & $1 \%$ \\
\hline Other & $3 \%$ & $5 \%$ \\
\hline
\end{tabular}

Out-of-state visitors had lower annual household incomes than Texas residents who visited state parks (Table 14). The median income for out-of-state visitors was $\$ 40,000-\$ 59,999$ compared to $\$ 60,000-\$ 79,999$ for visitors who lived in Texas. This difference is likely due to a higher percentage of out-of-state visitors being retired and having a fixed income as indicated by the distribution of ages of out-of-state visitors. 
Table 14

Household Income

Comparison of Survey Respondent Demographics

\begin{tabular}{|l|c|c|}
\hline & Out-of-state visitors & Visitors who live in TX \\
\hline Under $\mathbf{\$ 2 0 , 0 0 0}$ & $7 \%$ & $6 \%$ \\
\hline $\mathbf{\$ 2 0 , 0 0 0 - \$ 3 9 , 9 9 9}$ & $21 \%$ & $18 \%$ \\
\hline $\mathbf{\$ 4 0 , 0 0 0 - \$ 5 9 , 9 9 9}$ & $27 \%$ & $23 \%$ \\
\hline $\mathbf{\$ 6 0 , 0 0 0 - \$ 7 9 , 9 9 9}$ & $18 \%$ & $19 \%$ \\
\hline $\mathbf{\$ 8 0 , 0 0 0 - \$ 9 9 , 9 9 9}$ & $10 \%$ & $14 \%$ \\
\hline $\mathbf{\$ 1 0 0 , 0 0 0}$ or more & $17 \%$ & $20 \%$ \\
\hline Median & $\$ 40,000-\$ 59,999$ & $\$ 60,000-\$ 79,999$ \\
\hline
\end{tabular}

\section{CONCLUSIONS}

The vast majority of visitors to Texas state parks were residents of the state of Texas. These visitors were predominantly white/non-Hispanic, were older and had higher annual incomes than the average Texas resident, and were most likely to reside in urban areas of Texas. These data indicate that the typical visitor to Texas state parks is likely to be white/non-Hispanic, older than the average Texas resident, and have a greater disposable income than the average Texas resident.

In addition, out-of-state visitors were older, on average, than resident Texan visitors and, as a group, were more likely to make an overnight visit to a state park. It is likely that more out-of-state visitors were retired, as indicated by the age of these visitors, therefore having more time available to spend in the parks, and more likely to stay overnight because of the distance travelled to the park.

It is also important to note that even though a larger number of visitors to the state parks resided in urban areas of Texas, a greater percentage of all visitors resided in rural parts of the state compared to the general population of Texas. These data indicate that rural Texans are more likely to visit state parks than their urban counterparts.

\section{AUTHOR INFORMATION}

Dr. Marcy Beverly is an Associate Professor in the Department of Agricultural \& Industrial Sciences at Sam Houston State University. Research analysis she has performed include the Texas Department of Agriculture's Texas Public School Nutrition Program (Square Meals), the Texas Yes! Hometown STARS Program (Rural Tourism), the Texas Wine Marketing Assistance Program, and the GO TEXAN Marketing Program. Additional research she has performed includes market data analysis of consumer preferences for private branded beef.

Dr. Michael Lau is a trained econometrician and has extension experience in survey design and analysis. Dr. Lau has worked on a number of projects at SHSU being the principle investigator or co-principle investigator. He has performed survey design and analysis for recently TDA on the Texas Wine Marketing Assistance Program, Organic Market Barriers, and Wine Market Strategic Plan. In his time at SHSU, Dr. Lau has secured over \$340,000 in research funding with eleven peer-reviewed journal articles and forty-one peer-reviewed professional presentations.

Kyle J. Stutts, Ph.D. is currently an assistant professor of animal science in the Department of Agriculture and Industrial Sciences at Sam Houston State University. Dr. Stutts holds a bachelor of science degree in animal science from Texas A\&M University, a master of science degree in animal science from Oklahoma State University, and a doctor of philosophy degree in reproductive physiology from Texas A\&M University. Prior to coming to SHSU, Dr. Stutts held the position of livestock specialist with the Noble Foundation in Ardmore, OK and served as a consultant to agricultural producers in Oklahoma and Texas.

Dr. Dominick E. Fazarro is an Associate Professor in the Department of Agricultural and Industrial Sciences at Sam Houston State University. He has eight years of consulting experience conducting evaluation. Dr. Fazarro provided consulting services for University of Arkansas at Pine Bluff, Edu-Care International, Arkansas Department 
of Health \& Human Services, and Pulaski Special County School District. For two years at the University of Arkansas-Pine Bluff, Dr. Fazarro served as the Data Manager of a NSF/STEM HBCU-UP Grant, data manager for Standard Two--National Accreditation for Teacher Education (NCATE), and Evaluation Committee Chair for university accreditation-North Central Association Accreditation (NCA).

\section{NOTES}

